\title{
Determination of the equivalent intergranular void ratio - Application to the instability and the critical state of silty sand
}

\author{
Trung-Kien Nguyen ${ }^{1}$, Nadia Benahmed ${ }^{2, *}$, and Pierre-Yves Hicher $^{3}$ \\ ${ }^{1}$ Geotechnical Engineering Division, University of Transport Technology, Hanoi, Vietnam \\ ${ }^{2}$ Irstea, RECOVER Research Unit, IRSTEA, Aix-en-Provence, France \\ ${ }^{3}$ Ecole Centrale de Nantes, France
}

\begin{abstract}
This paper presents an experimental study of natural Camargue silty sand mechanical behavior. The analysis of test results was based on the use of the equivalent intergranular void ratio instead of the global void ratio. The calculation of equivalent intergranular void ratio requires the determination of parameter $\mathrm{b}$ which represents, physically, the fraction of active fines participating on the chain forces network, hence on the soil strength. A new formula for determining the parameter $b$ using an approach based on the coordination number distribution and probability calculation is proposed. The validation of the developed relationship was done through back-analysis of published datasets in literature on the effect of fines content on silty sand behavior. It is shown that the equivalent intergranular void ratio calculated with the $b$ value obtained by the new formula is able to provide a strong correlation, not only at the critical state, but also at the onset of instability of various silty sands, in different terms such as peak deviator stress, peak stress ratio or cyclic resistance. Therefore, it is suggested that the use of the equivalent void ratio concept and the new formula that we have put forward for $\mathrm{b}$ determination is highly desirable in predicting of silty sand behavior.
\end{abstract}

\section{Introduction}

The effect of fines content is an important parameter to take into account when evaluating the mechanical behavior of silty sand since it is widely encountered in nature. Several alternative density variables were proposed in order to better capture the mechanical response of this kind of material like, for example, the intergranular void ratio [1] and the specific relative density [2]. However, the analysis results adopting these density variables are still controversial.

In the sand-dominated sand-fine mixture like silty sand, according to Thevanaygam et al. [3], there are inactive fine particles that stay in the voids created by coarse grains and do not contribute to material resistance) and active fine particles that touch and separate the coarse grains. In order to take into account either active and inactive fine particles, a new density variable was proposed: the equivalent intergranular void ratio which is calculated as follows:

$$
e^{*}=\frac{e+(1-b) f_{c}}{1-(1-b) f_{c}}
$$

where $e$ is the void ratio, $f_{c}$ is fines content and $b$ is the fraction of active fines.

Many authors afterward reported that the equivalent intergranular void ratio has strong correlation with many aspects of silty sand mechanical behavior [3]-[12]. The main purpose of this work is to verify the effectiveness of the equivalent intergranular void ratio concept in characterizing the mechanical behavior of natural silty sand.

\section{Experimental procedure}

The soil used in this study is poorly graded natural Camargue silty sand which was taken from flood protection dikes. The clean sand and clean fines were separated by sieving the silty sand in order to prepare different mixtures. The sand is uniform with angular and rounded grains, a uniformity coefficient $\mathrm{C}_{\mathrm{U}}=2.09$ and an effective diameter $\mathrm{D}_{50}=0.25 \mathrm{~mm}$. Its minimum and maximum void ratio is equal to 0.61 and 1.10 , respectively. The fines used are low plastic fines with a liquid limit $\mathrm{W}_{\mathrm{L}}=32$ and a plasticity index $\mathrm{IP}=8$. The host sand and host silt were blended together to obtain the different mixtures with the different desired target fines contents (by weight) varying from $0,5,10,15$ and $20 \%$. The grain size distributions of all the materials tested in this study are presented in Figure 1.

A fully computed controlled Dynamic Triaxial System from Wykeham Farrance was used. The axial load was monitored by an internal submersible load transducer while the axial displacement was measured by an LVDT mounted on the top platen. The volume variation of the sample was determined by an automatic volume change device.

Corresponding author: nadia.benahmed@irstea.fr 


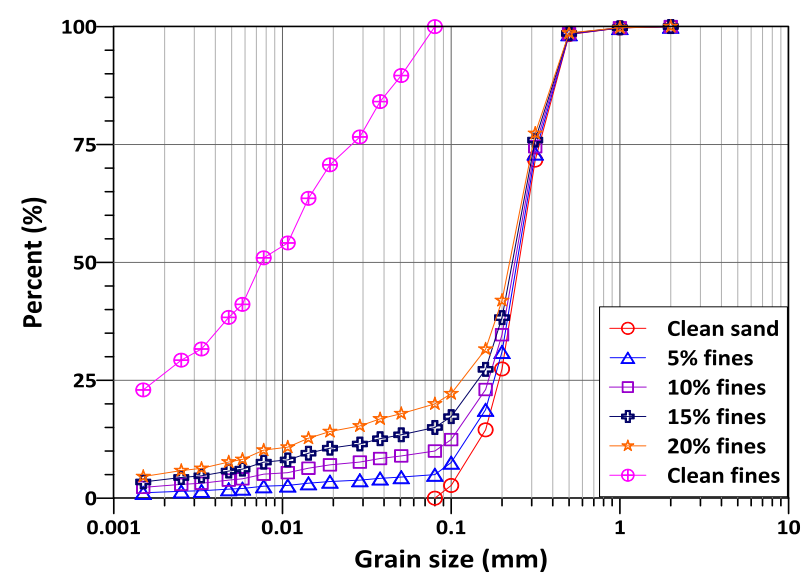

Fig. 1. Grain size distribution curves.

The soil samples of $140 \mathrm{~mm}$ height and $70 \mathrm{~mm}$ diameter were prepared by the moist tamping method. Particular care was taken to avoid any potential segregation, especially in the case of high fines content. To saturate the specimens, $\mathrm{CO}_{2}$ was flushed under a pressure of $20 \mathrm{kPa}$ during 30 minutes, followed by deaired water of about three times the specimen volume. Back pressures ranging from 400 to $500 \mathrm{kPa}$ were then applied to ensure full saturation of the specimens and to obtain a Skempton coefficient B higher than 0.96.

\section{Experimental results}

In order to investigate the effect of fines content on the behavior of Camargue silty sand, several triaxial tests were performed under both drained and undrained conditions. More details on the experimental program can be found in [13].

\subsection{Instability analysis}

Figure 2 shows the evolution of the deviator stress versus the axial strain in undrained tests of different mixtures. We note that all the curves show a very clear peak of resistance appearing at low axial deformation, followed by a sudden decrease until reaching a low (or null) residual shear strength.

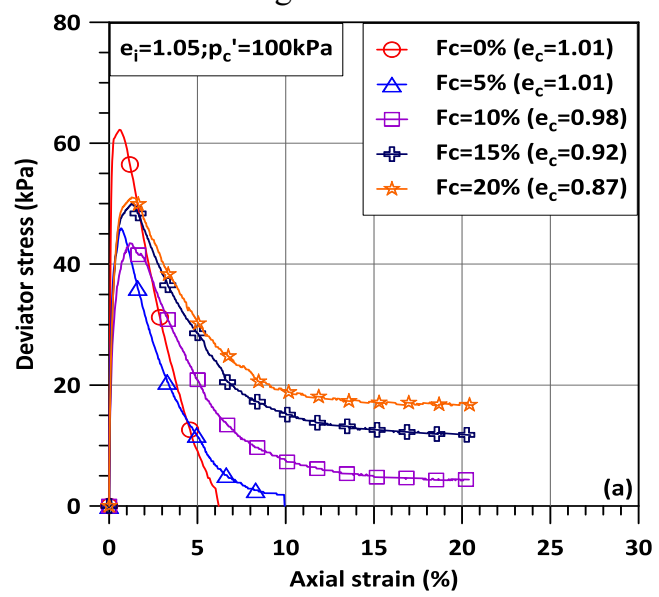

Fig. 2. Effects of fines content on undrained response of silty sand
In order to point out the effect of fines content on the onset of the instability, we reported in Figure 3 the peak deviator stress of all the tests against the postconsolidation void ratio. It is obvious that there is no unique relation between peak deviator stress and void ratio. Indeed, each mixture forms a different line. It is interesting to note that with the increasing of fines amount until $\mathrm{Fc}=20 \%$, this line moves downward. In other words, for a given post-consolidation void ratio, more the fines content is high, more the peak deviator stress is small.

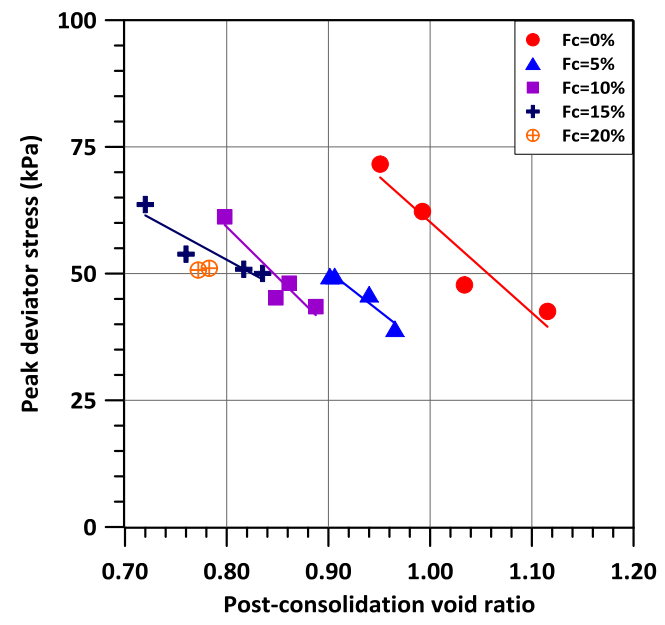

Fig. 3. Correlation between the peak deviator stress and the void ratio

\subsection{Critical state}

In this study, all the tests in drained conditions were conducted up to $30 \%$ of axial strain. Most of them have reached a stable state of both volumetric strain and deviator stress. We report in Figure 4 all points obtained at critical state for different mixtures as well as for the clean sand and the clean fines. It is interesting to note that each mixture has a different critical state line, which implies that the addition of fines particles creates different materials. The critical state line moved downward to a lower void ratio as the fines content increased up to $15 \%$. Similar results were reported by other authors in literature.

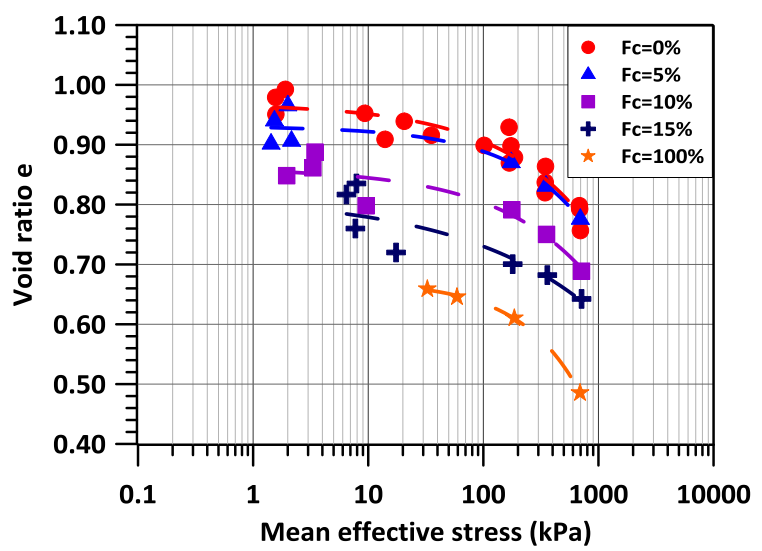

Fig. 4. Critical state lines in e - logp' space 


\section{Application of the equivalent intergranular void ratio}

In this section, the equivalent intergranular void ratio was used to analyze the obtained experimental results. In order to calculate this density variable, it was necessary to determine the $\mathrm{b}$ parameter value. Some authors identified this value by back-analysis in order to obtain the best fit to their experimental data [4], [7]. This means that the value of $b$ was chosen arbitrarily and it is a constant for a certain range of fines percentage. By using semi-empirical approach, Rahman et al. introduced the first formula to estimate the parameter $b$ as follows [10]:

$$
b=\left[1-\exp \left(-2.5 f_{c}^{2} / k\right)\right]\left(r f_{c} / f_{\text {thre }}\right)^{r}
$$

where $r=d_{50} / D_{10}\left(d_{50}\right.$ is mean diameter of fines particles whereas $\mathrm{D}_{10}$ is effective diameter of sand particles); $\mathrm{k}=1$ $\mathrm{r}^{0.25} ; \mathrm{f}_{\text {thre }}$ is the threshold fines content (the fines content that separates the sand-dominated structure and the fines-dominated structure).

Mohammadi and Qadimi evaluated the formula (2) with more datasets and reported that this formula does not work for 9 datasets out of 17 [12]. In addition, the $b$ parameter calculated by the equation (2) does not depend on the void ratio, which is not reasonable physically. Therefore, based on these observations, we developed a new formula to calculate the parameter $b$.

The basic idea of the new approach assumed that in three-dimensional space, a certain particle cannot move freely if it is "stucked" between at least four other particles. When the structure is loaded, such a particle could transmit forces. Thus, an active fine must have the coordination number greater than or equal to 4 and conversely, an inactive fine must have the coordination number smaller or equal to 3 .

Since many researchers reported that the distribution of the coordination number can be represented by the normal distribution or Gaussian distribution [14]-[19], the fraction of inactive fine (1-b) can then be calculated as the integral of the probability density function of the normal distribution, from 0 to 3.5:

$$
1-b=\frac{1}{\sigma \sqrt{2 \pi}} \int_{x=0}^{x=3.5} \exp \left(-\frac{\left(\mathrm{x}-\overline{C_{S}}\right)^{2}}{2 \sigma^{2}}\right) d x
$$

where $\mathrm{C}_{\mathrm{S}}$ and $\sigma$ are respectively the mean value and the standard deviation of the coordination number distribution of the fine particles.

Then, it is necessary to relate these two parameters to the material parameters. Since the researches in literature reported generally the results on the mean coordination number of an homogenous mixture, we need to develop a physical model of the coordination number of the binary mixture, that give us the following relationship:

$$
\overline{C_{S}}=4.7\left(1-f_{C}+2 f_{C} X\right) /\left(X\left(e+f_{C}\right)\right)
$$

where $\mathrm{X}=\mathrm{D}_{50} / \mathrm{d}_{50}$

A relation between $\sigma$ and $C_{S}$ can be obtained by approximating the experimental results reported by Oda as follows [17]:

$$
\sigma=2 \bar{C}_{S}
$$

So, we obtain the final equation to calculate $b$ parameter as follows:

$$
b=1.3-\left[1+\exp \left(0.85-0.63 \frac{e X+f_{c} X}{1-f_{c}+2 f_{c} X}\right)\right]^{-1}
$$

In order to evaluate the applicability of the new proposed formula, apart from the results of the current study, we reanalyzed 14 others datasets published in the literature, divided into two groups. The first one related to the instability onset and the second one related to the critical state. These results were presented in original papers, for the first group, as different relations between the classical void ratio and one instability parameter (peak deviator stress, peak stress ratio, cyclic liquefaction resistance), whereas for the second group as different critical state lines with the fines contents.

The back-analysis procedure of one dataset is processed as follows: the original data on void ratio, fines content and diameter ratio were collected in order to calculate the corresponding equivalent intergranular void ratio using the new formula. Then, we use the latter instead of void ratio and verify if we can obtain a single correlation presenting all dataset points. For an objective assessment, we adopted the benchmark used by Rahman et al. [10], following that the data points can be represented satisfactorily by a single correlation if the value of the root mean square deviation (RMSD) is smaller than 0.043 . In addition, we also reported the more popular coefficient of determination $\mathrm{R}^{2}$ for each obtained trend curve.

Among 16 back-analyzed datasets, the equivalent intergranular void ratio concept calculated with the $b$ parameter obtained from the new formula fails only in one case ([3]) and approaches the benchmark $(\mathrm{RMSD}=0.045)$ in three others cases $([9],[10],[20])$. It could be explained by the fact that in these cases, the sand and fines used have a very different mineralogy, while the concept of the equivalent intergranular void considers implicitly that the mechanical contributions of the sand grains and of fine grains are equals. For all the others cases, the equivalent intergranular void ratio concept calculated with the $\mathrm{b}$ parameter obtained from the new formula can be applied successfully, as shown for example in the case of the current study in Figure 5 and Figure 6.

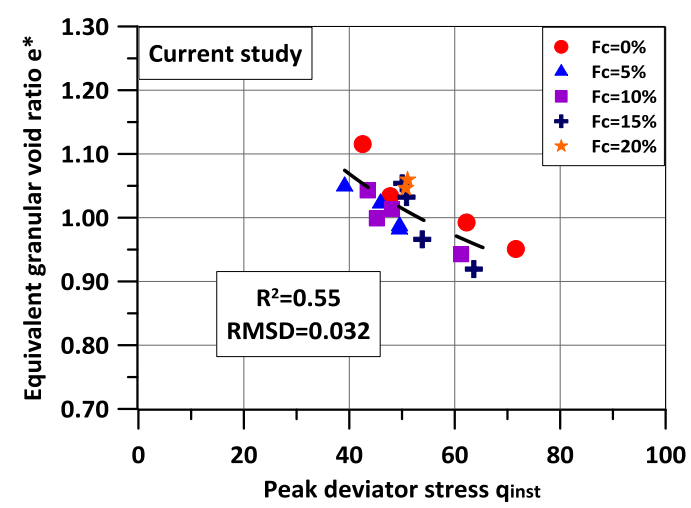

Fig. 5. Correlation between $\mathrm{q}_{\text {peak }}$ and $\mathrm{e}^{*}$ (calculated with the $\mathrm{b}$ obtained by the new formula) 


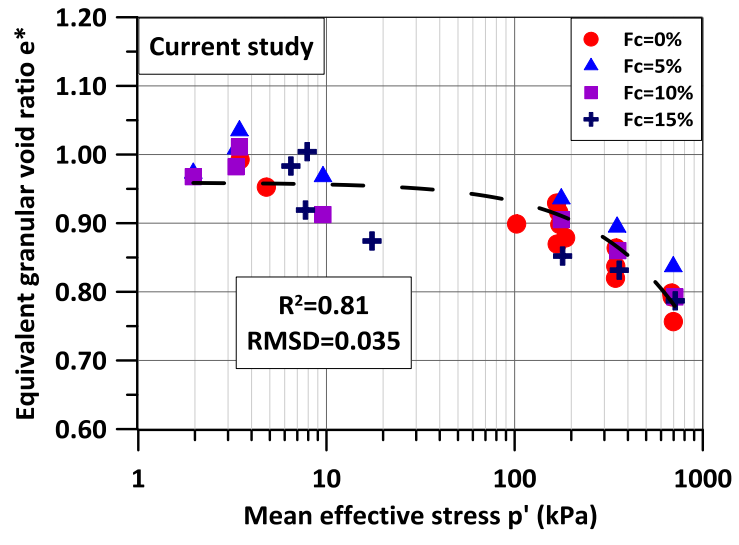

Fig. 6. Critical state line in $\mathrm{e}^{*}-\log \mathrm{p}^{\prime}$ space (e* calculated with the $b$ obtained by the new formula)

\section{Conclusion}

The equivalent intergranular void ratio appears to be a pertinent density variable in analyzing the mechanical response of silty sand. This alternative density variable showed a strong correlation with both the peak deviator stress and the mean effective stress at the critical state.

In order to calculate the equivalent intergranular void ratio, we proposed in this paper a new formula to compute the fraction of active fines based on the distribution of the coordination number. This new formula takes into account the effect of the fine content, the void ratio and the diameter ratio of the large and small grains. The back-analysis of many different datasets published in the literature confirmed the effectiveness of this formula with different materials, especially when the large and small grains have a similar mineralogy. Therefore, it is highly recommended to use the equivalent intergranular void ratio as an analysis variable in silty sand mechanical behavior prediction.

\section{References}

1. R. H. Kuerbis, D. Negussey, and Y. P. Vaid, "Effect of gradation and fines content on the undrained response of sand," Geotech. Spec. Publ., no. 21, pp. 330-345, (1988).

2. C. P. Polito and J. R. Martin II, "A reconciliation of the effects of non-plastic fines on the liquefaction resistance of sands reported in the literature," Earthq. Spectra, vol. 19, no. 3, p. 635, (2003).

3. S. Thevanayagam, T. Shenthan, S. Mohan, and J. Liang, "Undrained fragility of clean sands, silty sands, and sandy silts," J. Geotech. Geoenvironmental Eng., vol. 128, no. 10, pp. 849859, (2002).

4. Q. Ni, T. S. Tan, G. R. Dasari, and D. W. Hight, "Contribution of fines to the compressive strength of mixed soils," Géotechnique, vol. 54, no. 9, pp. 561569, (2004).

5. S. A. Naeini and M. H. Baziar, "Effect of fines content on steady-state strength of mixed and layered samples of a sand," Soil Dyn. Earthq. Eng., vol. 24, no. 3, pp. 181-187, (2004).
6. S. L. Yang, R. Sandven, and L. Grande, "Instability of sand-silt mixtures," Soil Dyn. Earthq. Eng., vol. 26, no. 2-4 SPEC. ISS., pp. 183-190, (2006).

7. S. L. Yang, R. Sandven, and L. Grande, "Steadystate lines of sand-silt mixtures," Can. Geotech. J., vol. 43, no. 11, pp. 1213-1219, (2006).

8. T. G. Murthy, D. Loukidis, J. A. H. Carraro, M. Prezzi, and R. Salgado, "Undrained monotonic response of clean and silty sands," Géotechnique, vol. 57, no. 3, pp. 273-288, (2007).

9. A. Papadopoulou and T. Tika, "The effect of fines on critical state and liquefaction resistance characteristics of non-plastic silty sands," Soils Found., vol. 48, no. 5, pp. 713-725, (2008).

10. M. M. Rahman, S.-C. R. Lo, and C. T. Gnanendran, "On equivalent granular void ratio and steady state behaviour of loose sand with fines," Can. Geotech. J., vol. 45, no. 10, pp. 1439-1456, (2008).

11. C. Stamatopoulos, "An experimental study of the liquefaction strength of silty sands in terms of the state parameter," Soil Dyn. Earthq. Eng., vol. 30, no. 8, pp. 662-678, Aug. (2010).

12. A. Mohammadi and A. Qadimi, "A simple critical state approach to predicting the cyclic and monotonic response of sands with different fines contents using the equivalent intergranular void ratio," Acta Geotech., May (2014).

13. N. Benahmed, T. K. Nguyen, P. Y. Hicher, and M. Nicolas, "An experimental investigation into the effects of low plastic fines content on the behaviour of sand/silt mixtures," Eur. J. Environ. Civ. Eng., vol. 18, Jul. (2014).

14. W. O. Smith, P. D. Foote, and P. F. Busang, "Packing of homogeneous spheres," Phys. Rev., vol. 34, no. 9, pp. 1271-1274, (1929).

15. J. D. Bernal and J. Mason, "Co-ordination of randomly packed spheres," Nature, vol. 188, pp. 910-911, (1960).

16. M. Akarawa and M. Nishino, "Contact number and porosity in randomly packed sphere mixtures," J. Soc. Mater. Sci. Japan, vol. 22, pp. 658-662, (1973).

17. M. Oda, "Co-ordination number and its relation to shear strength of granular material," Soils Found., vol. 17, no. 2, pp. 29-42, (1977).

18. J. S. Goodling and M. S. Khader, "Co-ordination number cylindrical bed distribution of spherical particles in a packed," Powder Technol., vol. 44, no. 1, pp. 53-55, (1985).

19. R. Y. Yang, R. P. Zou, and A. B. Yu, "Computer simulation of the packing of fine particles," Phys. Rev. E. Stat. Phys. Plasmas. Fluids. Relat. Interdiscip. Topics, vol. 62, no. 3 Pt B, pp. 39003908, Sep. (2000).

20. C. P. Polito, "The effects of non-plastic and plastic fines on the liquefaction of sandy soils," Virginia Polytechnic Institute, (1999). 